\title{
Research Paper \\ Comparison of Motion Control Screening Test Scores in Active Women with a History of Knee and Ankle Injuries
}

\author{
${ }^{*}$ Maryam Golmoradi Marani ${ }^{1}\left(\mathbb{D}\right.$, Amir Letafatkar ${ }^{2}$ (1), Seyed Sadredin Shojaedin² (1)
}

1. Department of Corrective Exercise and Sport Injury, Faculty of Physical Education and Sport Sciences, Kharazmi University, Tehran, Iran. 2. Department of Health and Sports Medicine, Faculty of Physical Education and Sport Sciences, Kharazmi University, Tehran, Iran.

\begin{tabular}{|c|c|}
\hline $\begin{array}{l}\text { Use our devict to scan } \\
\text { and read the article online }\end{array}$ & $\begin{array}{l}\text { dtation: Golmoradi Marani M, Letafatkar A, Sadredin Shojaedin S. [Comparison of Motion Control Screening Test Scores } \\
\text { in Active Women with a History of Knee and Ankle Injuries (Persian)]. Journal of Sport Biomechanics. 2021; 7(1):56-67. https:// } \\
\text { doi.org/10.32598/biomechanics.7.1.4 } \\
\text { dol'https://doi.org/10.32598/biomechanics.7.1.4 }\end{array}$ \\
\hline
\end{tabular}

\section{(c) (i) (5)}

Article Info:

Received: 06 Feb 2021 Accepted: 26 Apr 2021 Available Online: 01 Jun 2021

Keywords: Movement Control, Injury Prevention, Cut-off point

\section{ABSTRACT}

Objective Commenting on the return to sport after some injury is in doubt. The aim of this study was to investigate the relationship between test scores of movement control and a history of knee and ankle injury in active females.

Methods Statistical population of this study was 57 active females ( 22 healthy subjects, 19 subjects with a history of previous knee injury and 16 subjects with a history of previous ankle injury) with age ranging from 18 to 25 years old. In order to evaluate subjects, were used to the movement control test set consists of nine separate questions. Total maximum points in the subtests were 40 points, which less point was a better result in these tests. For statistical analysis, Kolmogorov-Smirnov test, Levene test, analysis of variance (ANOVA) and Tukey test were used (Significant at $95 \%$ and the alpha less than or equal 0.05 , and using of the SPSS software v. 22).

Results The results of this study showed test scores of movement control earned by females with a history of ankle and knee injuries was significantly different with the healthy females $(P=0.001)$.Compare scores of subjects with contact and non-contact injuries with healthy women showed that contact injury had higher scores than those who are non-contact injuries. The differences between the groups with any of these injuries are significant with no injury group ( $P=0.001)$.Cut-off point for this test was about 15.5 . Conclusion The scores of functional movement screening give a detailed model of the injury prevention to coaches in order to predict the risk of lower extremity injuries in athletes. So its need to coaches in order to the prevention of sports injuries, use the functional movement screening tests. To measure the performance level of the athletes before the start of the season, in order to identified athletes that are at risk of injury, in order to improve their capabilities.

\section{Extended Abstract}

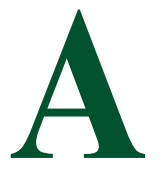

\section{Introduction}

lthough the benefits of exercise have always been important in maintaining the health of society, at the same time, sports activities are a risk factor for causing traumatic injuries among athletes [1]. Today, with the increasing tendency of young people to play sports, the rate of sports injuries is also increasing [2]. According to the National Collegiate Athletic Association, about 182,000 sports injuries occurred between 1988 and 2004, with knee and ankle injuries being the most common [3]. Research has also revealed that women are more likely than men to be injured during exercise [4-6].

\section{* Corresponding Author:}

Maryam Golmoradi Marani, MA.

Address: Department of Corrective Exercise and Sport Injury, Faculty of Physical Education and Sport Sciences, Kharazmi University, Tehran, Iran.

Tel: +98 (914) 9529241

E-mail: maryam.golmoradi@yahoo.com 
In order to prevent sports injuries, having basic knowledge of biomechanics, anatomy, physiology and kinesiology is essential [7]. By recognizing the causes of injury, we can invest in areas that prevent injury and avoid further occurrence or progression of injury [8]. One of the most important causes of injury is motion control disorders, the identification and correction of which is recognized as an important part of injury assessment and rehabilitation [9]. Neuromuscular control, central instability, and muscle imbalance have also been identified as contributing factors to injury [10-12].

Due to the increasing incidence of sports injuries, pre-season screening of athletes is common nowadays [7]. These screenings as part of injury risk management strategies can be useful in predicting re-injury $[13,14]$. Therefore, with the increasing need to identify the probability of injury with high accuracy, a new method of screening has been developed. These tools are a set of motion control tests that can be used as a measurement tool to identify movement disorders using a set of polyarticular functional tests [14].

Pre-season screening of athletes can be very important and reduce injury time, improve motor function, and prevent injury before it occurs [7]. Therefore, the aim of this study was to investigate the relationship between the scores of motion control screening tests in active women with a history of injury, and to determine the predictive score for injury.

\section{Methods}

The statistical population of this study included all active women aged 18-25 years in Kharazmi University. Based on the inclusion criteria, 57 of them were selected as available samples. Thirty-five subjects had a history of lower limb injuries (19 with a history of ankle injuries and 16 with a history of knee injuries), of which 25 had nonimpact injuries and 10 had impact injuries.

In the test session, the examiner orally explained each of the tests to the participants. Then the test process started and after warming up for five minutes, the test was performed. During the tests, the participants' performance was videotaped from four different angles by four digital cameras and then used for scoring (required sequences were extracted by Corel protractor software). These tests lasted 25-30 minutes and included 9 tests: Double Knee Swing, Single leg 1/4 squat + hip turn, Bridge + straight leg lift \& lower, Controlled shoulder internal rotation, 4 point-arm reach forward and back, Plank+lateral twist, One arm wall push, Split squat+fast feet, Lateral stair hop+rotational landing control $[9,13]$. Each of these tests presents several criteria in the form of questions that require observational judgments about a person's ability to control movement with standard criteria (40 criteria in total), each of which was answered in the affirmative or negative. For statistical analysis, Kolmogorov-Smirnov test was used to check the normality of the data, Levene's test was used for data homogeneity, one-way ANOVA and Scheffe post hoc tests were used to examine the intergroup differences. Finally, the data were analyzed by SPSS software v. 22 (Table 1).

\section{Results}

In order to perform the one-way ANOVA statistical test, the assumption of normality of data and variance homogeneity in the variables under study was investigated. The results indicated that the assumption of homogeneity of variance and normality of data $(\mathrm{P}>0.05)$ was established in all research variables.

According to the results of ANOVA test, there was a significant difference in the scores of motion control test between the groups with a history of "ankle injury", "knee injury", and "no injury". Therefore, Scheffe post hoc test was used to investigate the differences between the means of all three experimental groups. The results of Scheffe test revealed that there was a significant difference in the scores of motion control tests between the "ankle injury" and "no injury" groups and also between the "knee injury" and "no injury" groups $(\mathrm{P}=0.001)$. The results revealed that the scores of these tests are lower for the "no injury" group than the "ankle injury" group, and relatively lower for the "ankle injury" group than the "knee injury" group, respectively. Therefore, the "no injury" group had the least motion control disorder and the "knee injury" group had the most.

Also, according to the results of the ANOVA and Scheffe statistical tests, there was a significant difference in the scores of motion control test between the "impact injury", "non-Impact injury" and "no injury" groups. The "impact injury" group had higher scores than the "non-impact injury" group, which indicates more motion control disorder.

Results of Scheffe test between the "impact injury", "non-Impact injury", "ankle injury", "knee injury" and "no injury" groups in motion control test scores. Drawing and analysis of the ROC curve revealed that the cut-off obtained for this test is 15.5 . 
Table 1. Results of the Scheffe statistical tests

\begin{tabular}{ccccc}
\hline Inferential statistics & Intergroup comparison & Mean Difference & Standard Error & Significance \\
\hline No injury & Ankle injury & 9.197 & 0.578 & 0.000 \\
No injury & Knee injury & 10.62 & 0.606 & 0.000 \\
Ankle injury & Knee injury & 1.42 & 0.626 & 0.067 \\
No injury & Impact injury & 9.65 & 0.736 & 0.000 \\
No injury & Non-impact injury & 9.93 & 0.564 & 0.000 \\
Impact injury & Non-impact injury & 0.28 & 0.722 & 0.921 \\
\hline & & & & Journal of \\
\end{tabular}

\section{Discussion and Conclusion}

The aim of this study was to investigate the relationship between the motion control test scores in active women with a history of injury and determine the predictive score to identify people prone to injury. The results indicated that the scores of motion control tests of the women with a history of ankle and knee injuries were significantly different from the scores obtained by women without lower limb injury ( $\mathrm{P}=0.001)$. Although the score of these tests was lower for the "ankle injury" group than the "knee injury" group, no significant difference was observed between the two groups. The results also revealed that there was a significant difference between the motion control scores of the "non-impact injury" and "impact injury" groups with the "no injury" group. While there was no significant difference between the "impact injury" group and the "nonimpact injury” group.

Many studies have examined the relationship between screening tests and the occurrence of injuries, and present screening test scores as a predictor of injury. In this study, a score of 15.5 was determined as the cut-off score (predictor) and in general, the participants who scored lower in the screening tests were less prone to injury. Therefore, in order to use these tests in diagnostic assessments and prevention of lower limb injuries, the probability of injury should be estimated in proportion to the individual's score.

This study was one of the first researches about the evaluation of lower limb motion control based on field tests. Sports coaches and sports injury prevention officials are advised to use the results of this study and other research related to sports injury prevention. In addition to performing medical tests, they can also use motion control screening tests as a valid tool, and thus by measuring the level of performance of athletes they can identify people at risk before the start of the competition season and can improve the athletes' abilities.

\section{Ethical Considerations}

\section{Compliance with ethical guidelines}

All ethical principles are considered in this article. The participants were informed about the purpose of the research and its implementation stages. They were also assured about the confidentiality of their information and were free to leave the study whenever they wished, and if desired, the research results would be available to them.

\section{Funding}

The study was extracted from MA. thesis of first author the Department of Corrective Exercise and Sport Injury, Faculty of Physical Education and Sport Sciences, Kharazmi University, Tehran.

\section{Authors' contributions}

All authors equally contributed to preparing this article.

\section{Conflicts of interest}

The authors declared no conflict of interest. 
مقاله يُورهشى

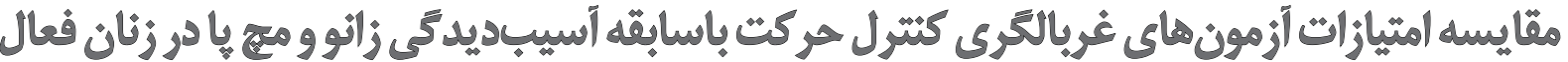

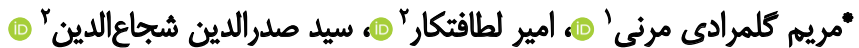 \\ ا. كروه آسيب شناسى وحركات اصلاحي، دانشكده تربيت بلنى و علوم ورزشى، دانشعاه خوارزمى، تهران، ايران.

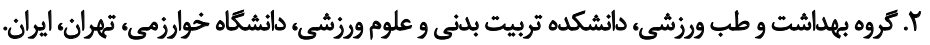

\begin{abstract}
حكيد

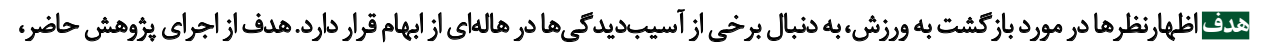

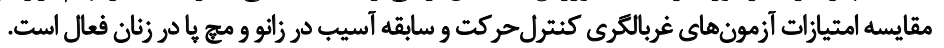

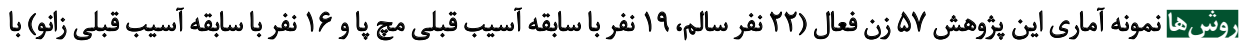

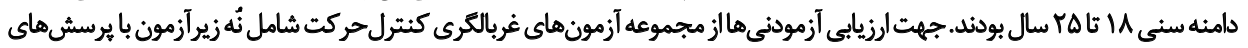

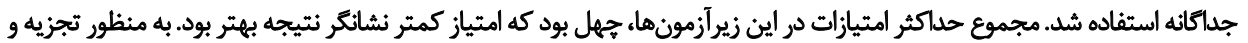

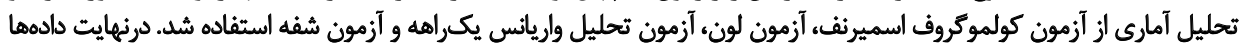

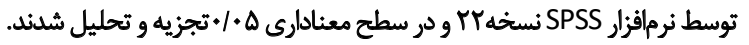

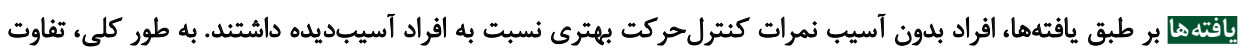

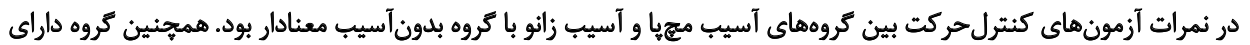

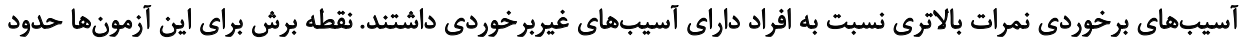
la/a

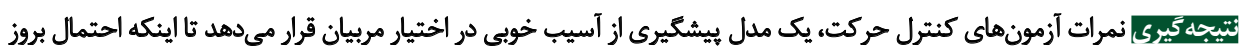

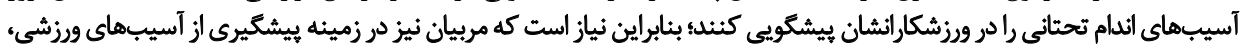

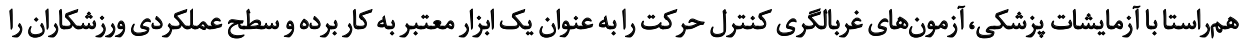

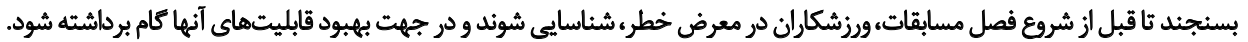

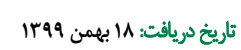

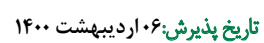

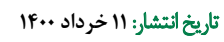

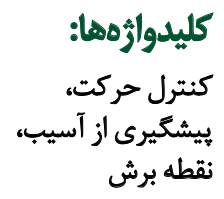

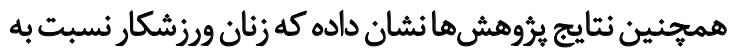

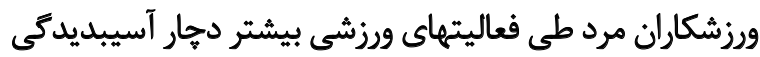

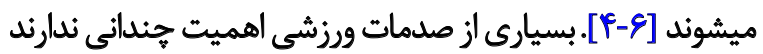

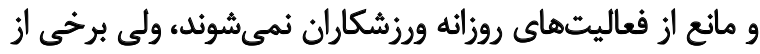

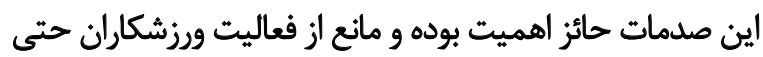
در سطوح هايين مىشوند [هائز اهميت بوده مان

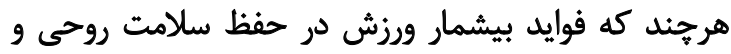

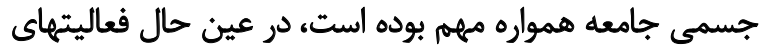

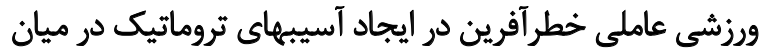

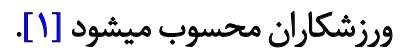
به منظور بيشكيرى از آسيبهاى ورزشى، داشتن اطلاعات يايه

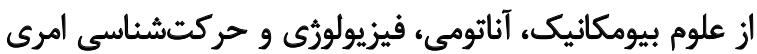

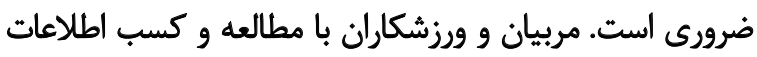

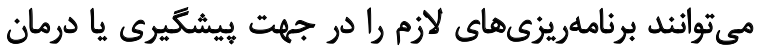
آسيبها داشته باشند [V] همواره در بررسى آسيبهاى ورزشى، بررسى علل بروز آن امروزه گرايش جوانان به ورزش افزايش يافته و با افزايش

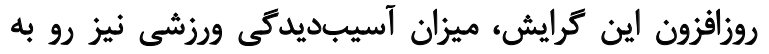

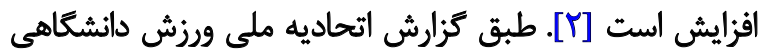

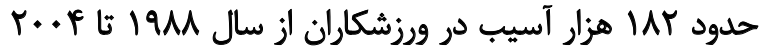

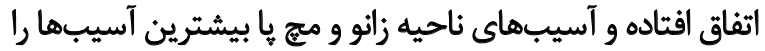

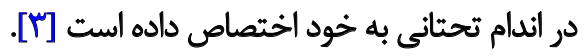

$$
\begin{aligned}
& \text { * *ويسئده مسئول: } \\
& \text { مريم كلمرادى مرنى نئي }
\end{aligned}
$$

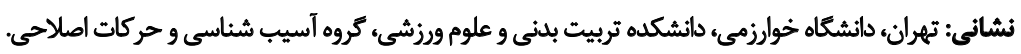

$$
\begin{aligned}
& \text { Tلفن: }
\end{aligned}
$$

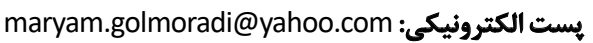




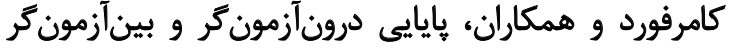

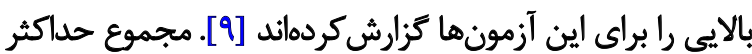

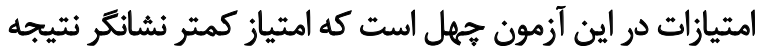

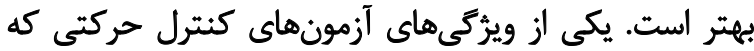

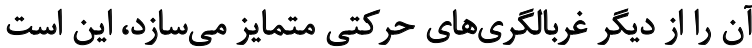

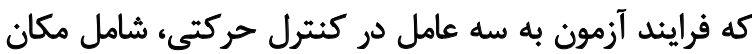

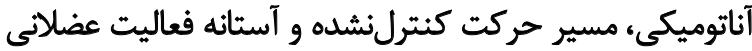

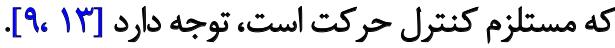

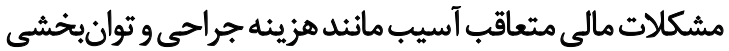

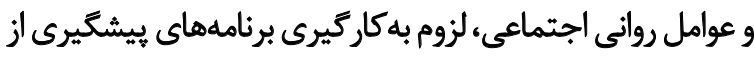

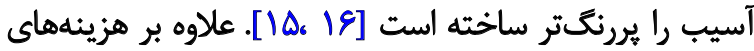

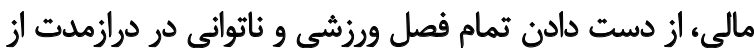

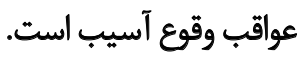

نظر به اينكه آسيبها باعث مىشوند تاورزشكاران زمان زيادى

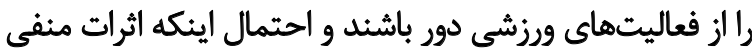

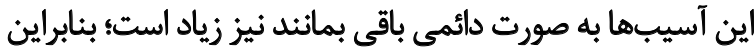

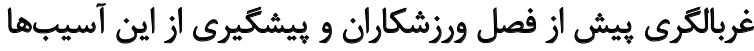

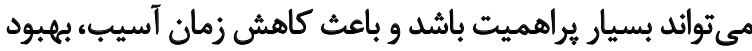

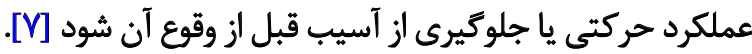

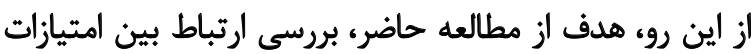

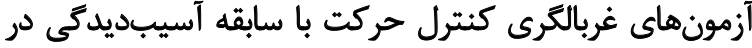

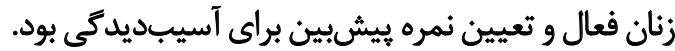

روش رشناسى

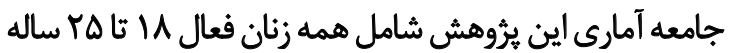

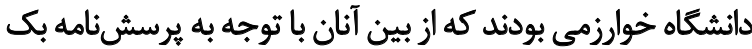

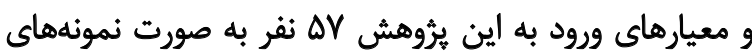

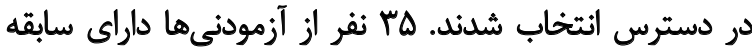

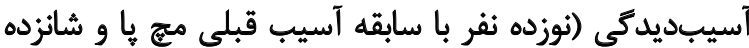

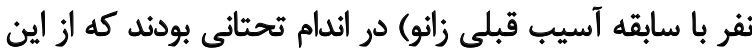

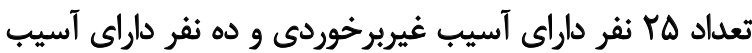

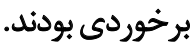

دستكاهها و وسايل مورد نياز براي اندازهكيرى شامل دوربين

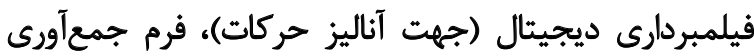

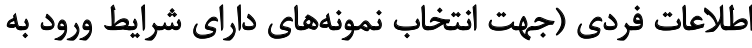

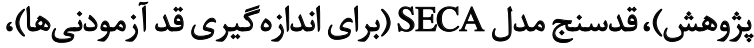

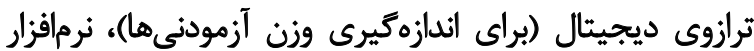

زاويهسنج كورل جهت بررسي سكانس هاي مورد نياز بود.

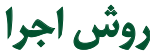

براى انتخاب آزمودنىها از فرم جمعآورى اطلاعات استفاده

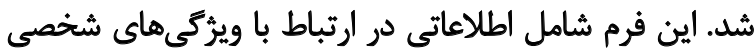

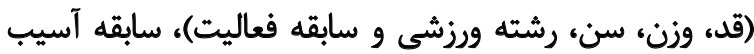

بخش مهمى به حساب مي آيد، به نحوى كه با شناخت عوامل

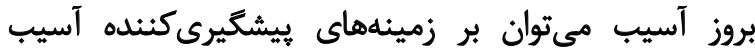

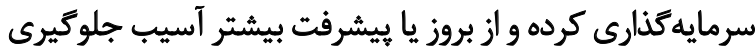

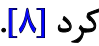

عوامل متعددى خطر آسيب را افزايش ميدهند، همواره

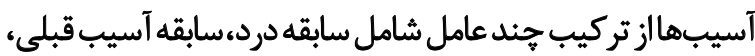

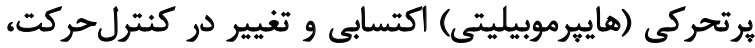

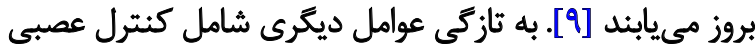

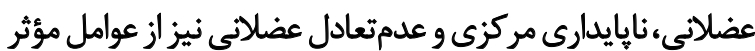

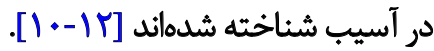

با توجه به افزايش وقوع آسيبهاى ورزشي، امروزه غربالكرى بيش

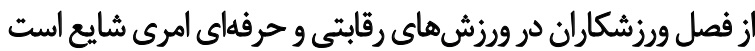

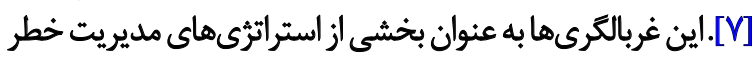

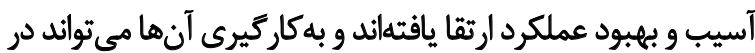

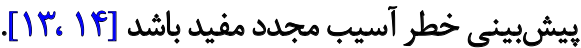

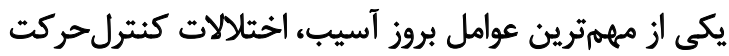

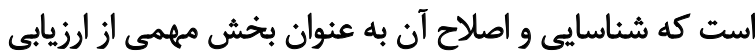

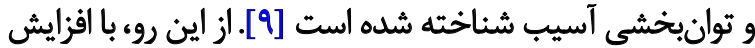

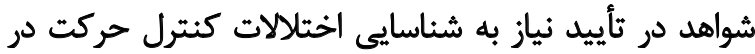

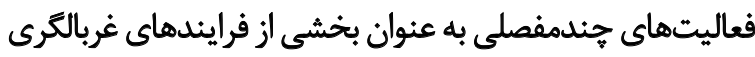

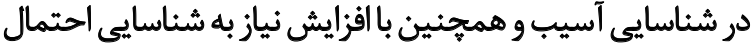
آسيب با دقت بالا، روش نوينى از غربالكرى ايجاد شده است.

اين ابزار مجموع آزمونهاي كنترل حركت هستند كه به منظور

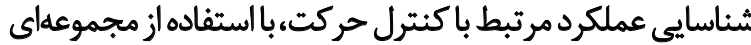

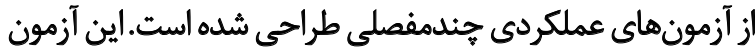

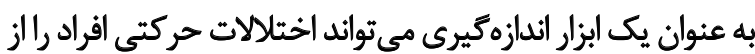

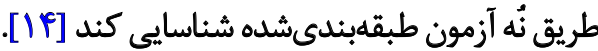
اين يروتكل جهث شناسايى كنترل حركت ناكارآمد (لينك

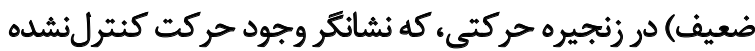

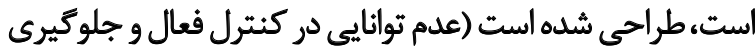

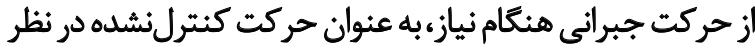

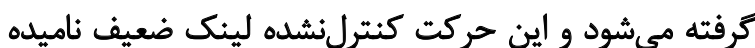

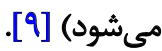

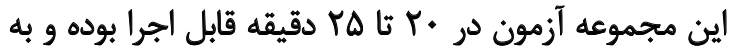

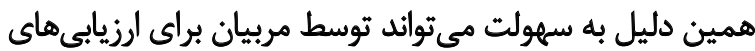

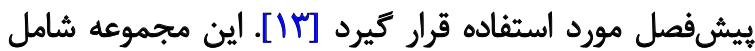

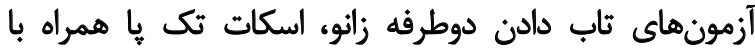

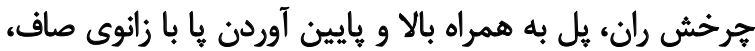

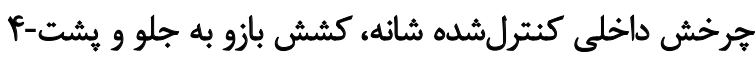

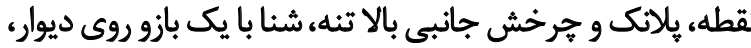

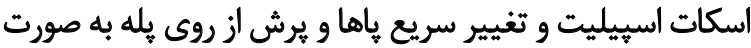

طرفى است [9]. 
جلو است، مىايستد. سيس زانوها را به اندازه أ أفلكشن كامل

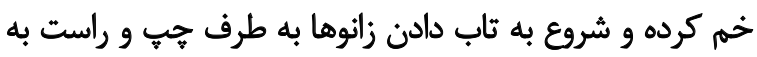

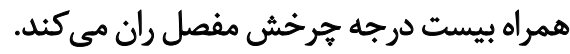
معيارهاى امتيازدهى براى اين آزمون شامل توانايى فرد در

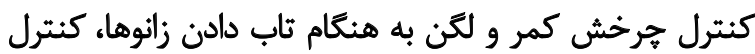

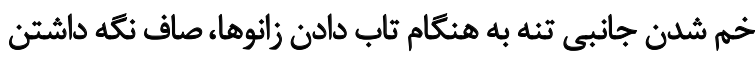

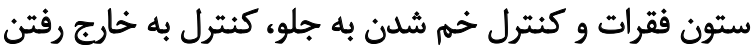

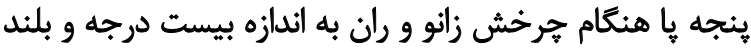

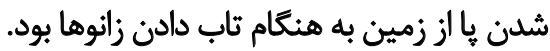

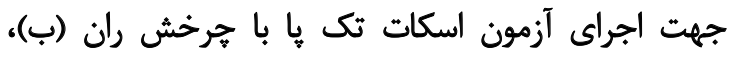

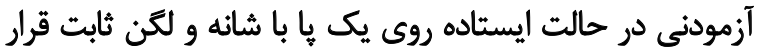

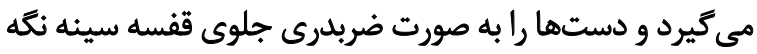

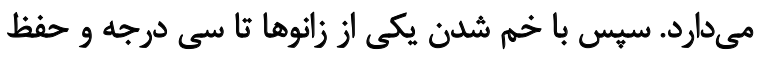

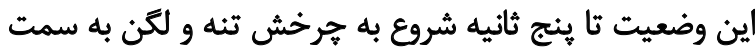

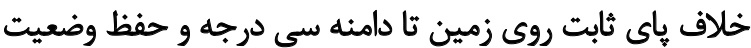

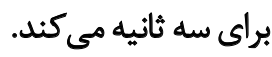

خعيارهاى امتيازدهى اين آزمون شامل بررسى توانايى فرد در

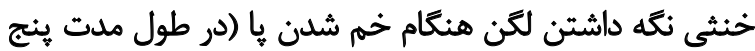

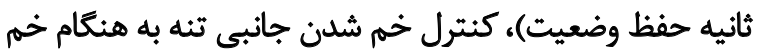

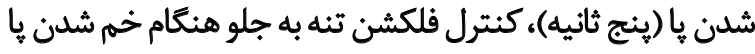

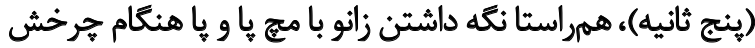

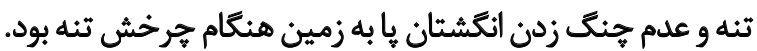

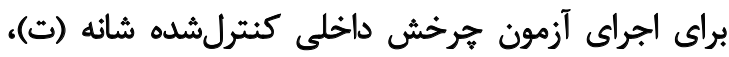

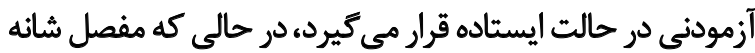

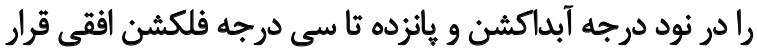

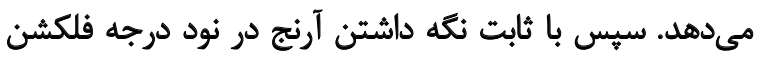

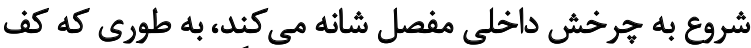

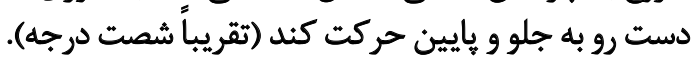

معيارهاى امتيازدهى شامل كنترل خم شدن به جنان جلو قسمت

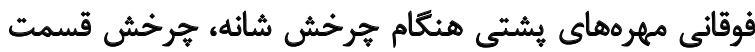

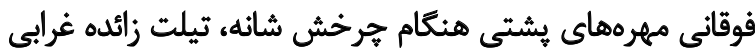

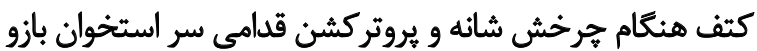

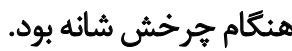

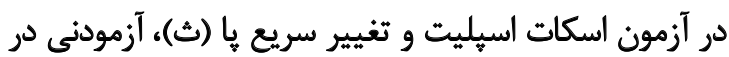

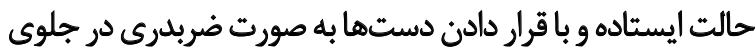

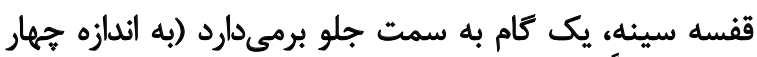

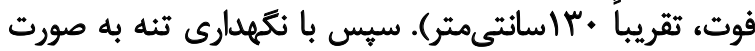

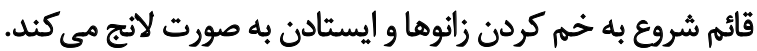

سيس با حفظ اين وضعيت شروع به تعويض سريع جاى هاهي

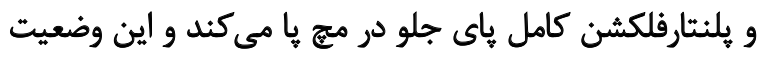
را براي بنج ثانيه حفظ مى كند. معيارهاى امتيازدهى بر براى اين واين

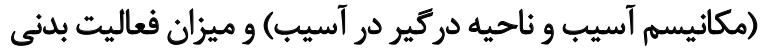

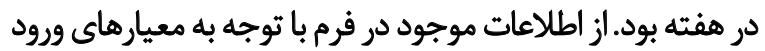
تعيينشده براى انتخاب آزمودنى هاى يرؤهش استفاده شدرد معيارهاى ورود يُروهش شامل عدم وجود درد، ناهنجارى

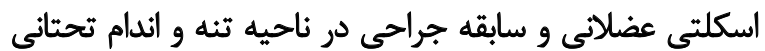

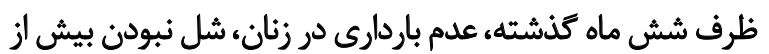

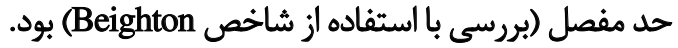

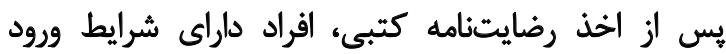

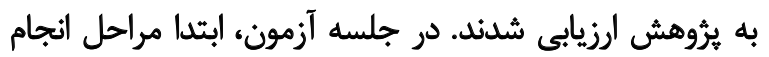

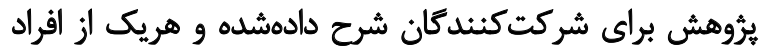

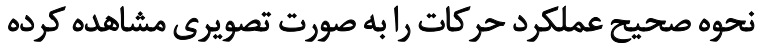

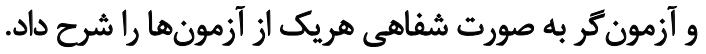

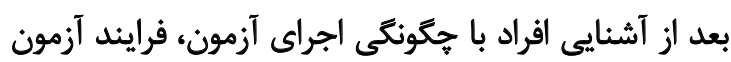

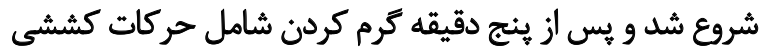

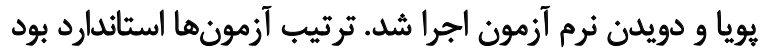

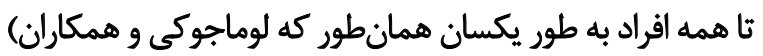

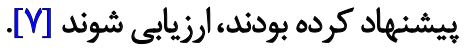

هنغام انجام آزمونها، عملكرد اقراد به وسيله جهار دوربين

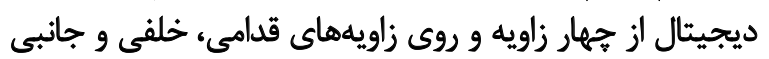

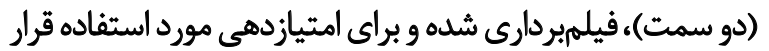

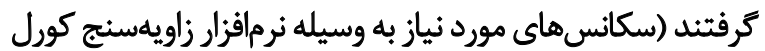

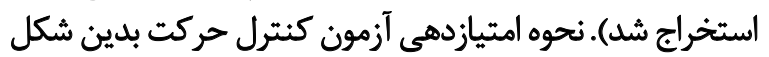

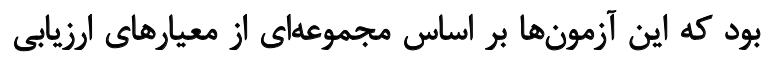

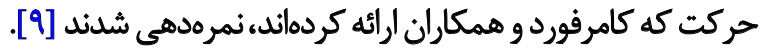
از آنجا كه هدف آزمونهاى كنترل حركت، اندازهكيرى

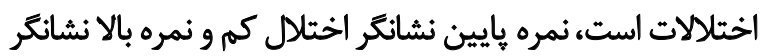

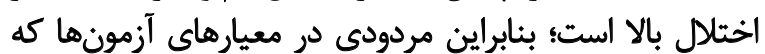

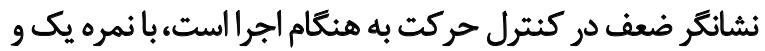

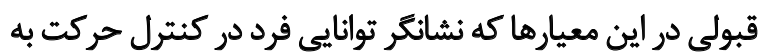
هنكام اجرا است، با نمره صفر نمرهدهى شد.

از آنجا كه مجموع معيارهاي سؤالى در اين آزمونها جهبل معيار

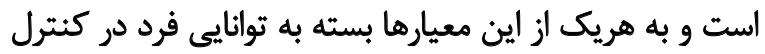

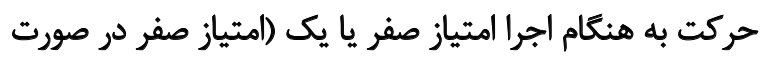

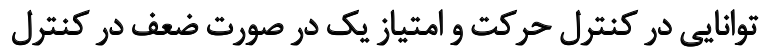

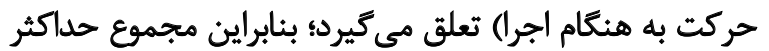

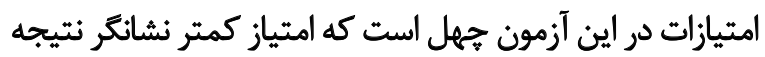

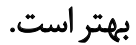
نحوه اجراو معيار ارزيابى و امتيازدهى اين نُه زيرآزمون به شرح ذيل است (تصوير شماره l):

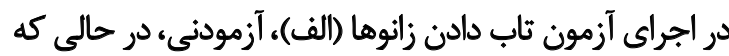

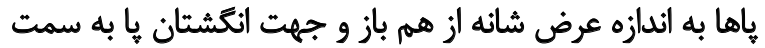




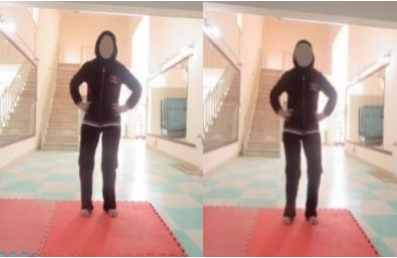

(الف)

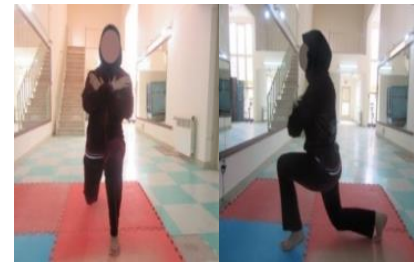

(ث)

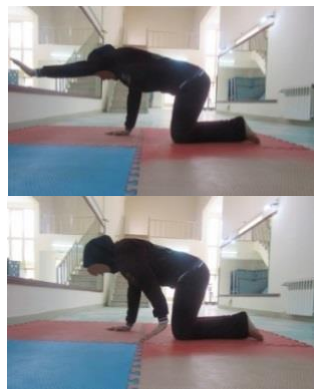

$(\tau)$

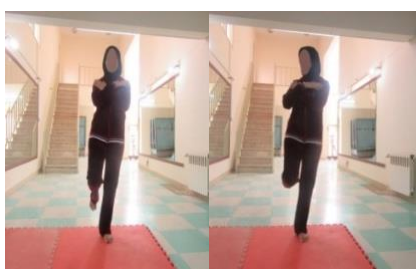

(ب)

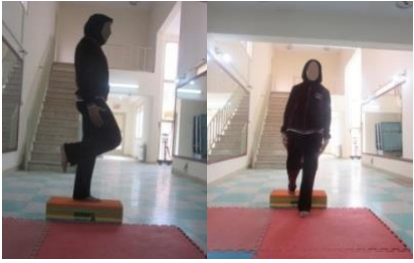

(ج)

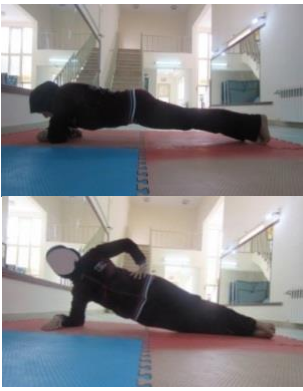

$(\dot{\tau})$

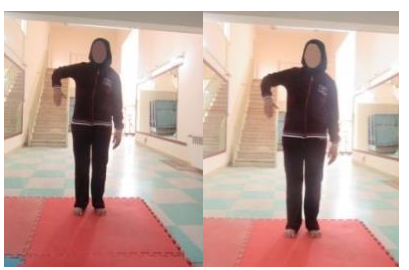

(ت)

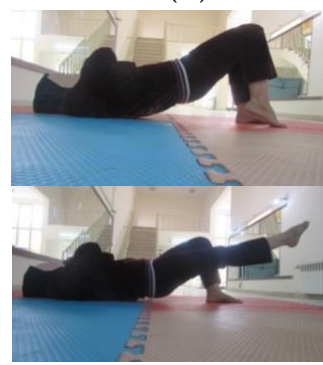

(ङ)

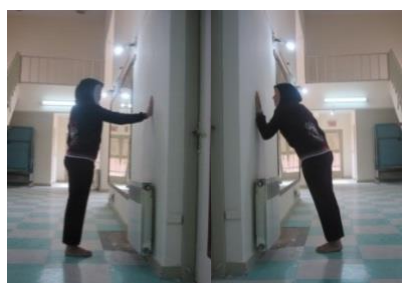

(ى)

مجله بيومكانيك ولنش

تصوير ا. مجموع آزمون هاى كنترل حركت

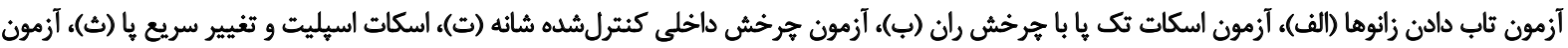

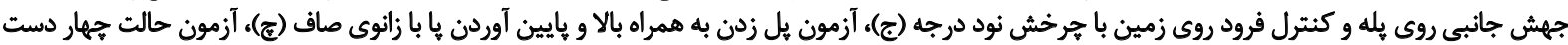

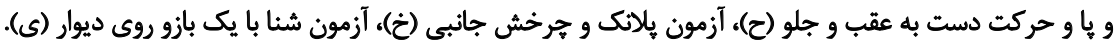

زدن انكشتان ها به زمين هنكام فرود بود.

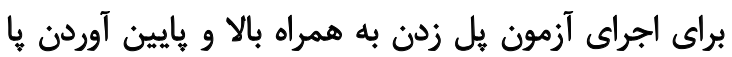

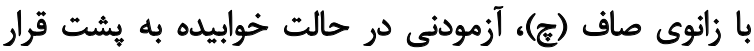

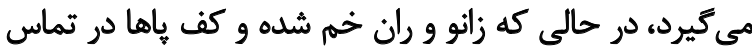

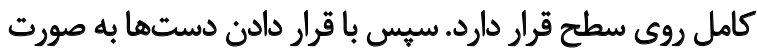

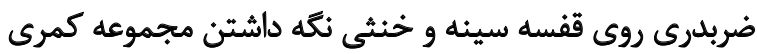

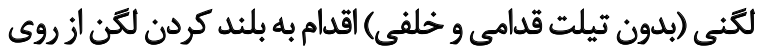

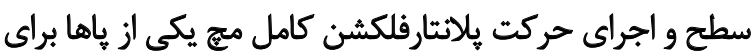

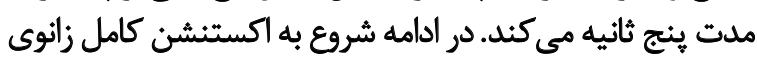

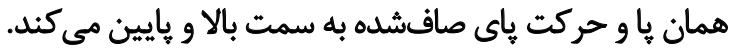
معيارهاى امتيازدهى اين آزمون شامل توانايى فرد در كنترل

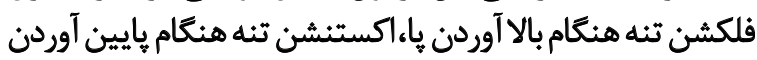

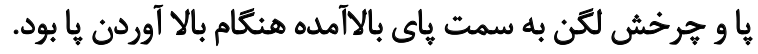

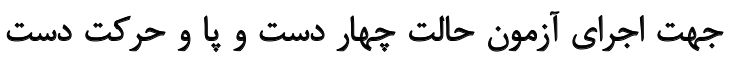

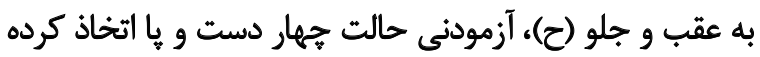

آزمون شامل كنترل خم شدن جانبى تنه هنعام اجرا، كنترل خما

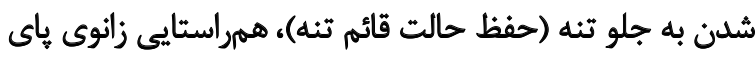

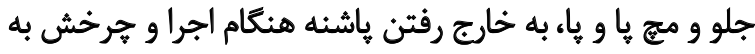
خارج ياشنه هنكام اجرا بود.

در اجراى آزمون جهش جانبى روى بله و كنترل فرود رودي

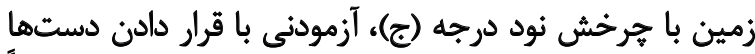

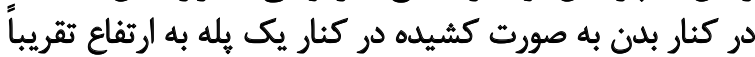

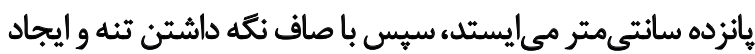

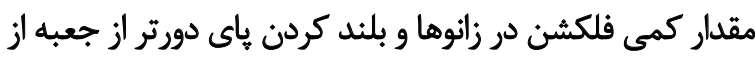

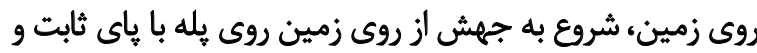

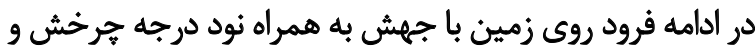
حفظ اين وضعيت براى ينج ثانيه مى كنئ.

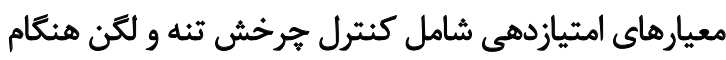

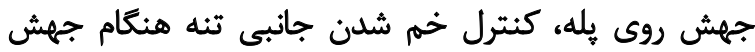

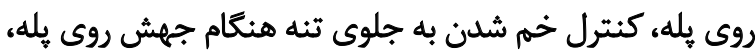

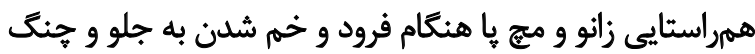


جدول ا. مشخصات جمعيتشناختى آزمودنى ها (ائحراف استانداردثميائكين)

\begin{tabular}{|c|c|c|c|}
\hline \multicolumn{3}{|c|}{ ميانغين } & \multirow{2}{*}{ 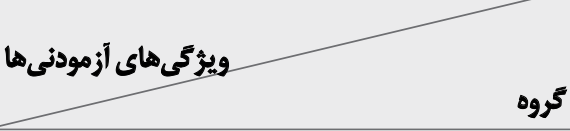 } \\
\hline سن (سال) & 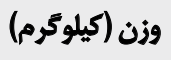 & قد (سانتىمتر) & \\
\hline$T Y / \Delta q \pm=/ T Y q$ & $\Delta N \Delta \pm \mid / F I$ & $\mid Q T / P \pm \cdot / N C Y$ & Sروه افراد فعال بلون سابقه آسيبديدكى (N=MY) \\
\hline$r V / \Delta Y \pm \cdot / F \cdot V$ & $8 \cdot / N \pm 1 / \% q$ & $\mid \varphi \Delta / r q \pm 1 / T q$ & كروه أقراد فعال با سابقه آسيبديدكى هج يا (N=19) \\
\hline$M N \cdot \pm \cdot / F Q$ & $\Delta V / f) \pm 1 / \cdot \Delta$ & $19 \Delta / \pi r \pm I / A$ & كروه اقراد فعال با سابيهه آسيبديدكى زانو (N=18) \\
\hline
\end{tabular}

مجله بيومكانيك وزنش

در آزمون شنا با يك بازو روى ديوار (ى)، آزمودنى با فاصلهاى

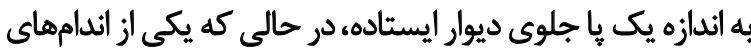

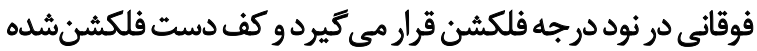

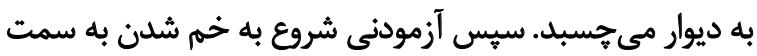

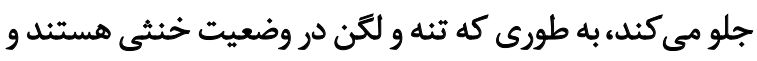

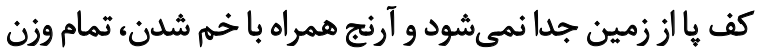
بلدن را تحمل مى كند.

معيارهاي امتيازدهي اين آزمون شامل توانايي فرد در كنترل

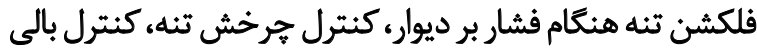

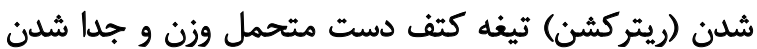

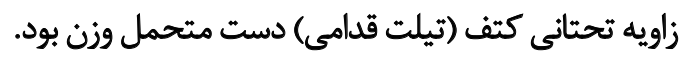
براي نرمال بودن دادهها از آزمون كولموكروف السميرنف

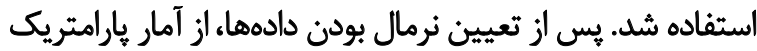

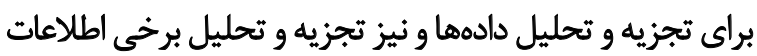

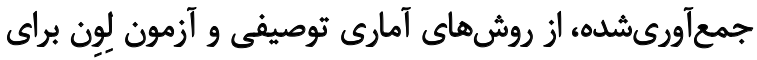
بررسى همكن بودن دادهها استفاده شد. همجنين براي بررسي ارتباط بين امتيازات آزمونهاي كنترل
و وزن بدن را روى يك دست مي اندازد. سيس شروع به حركت

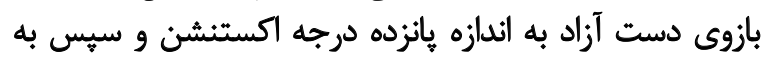

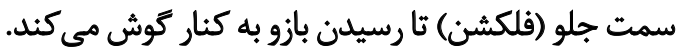
معيارهاى امتيازدهى براي اين آزمون شامل توانايى فرد در

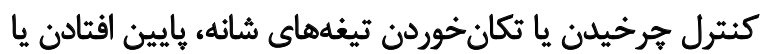

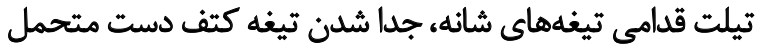
وزن و يروتراكشن قدامى شانه دست در حال حركئ حركت بود. براى اجراى آزمون يهلانك و جرخش جانبى (خ)، آزمونى در در

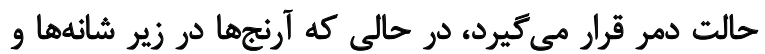

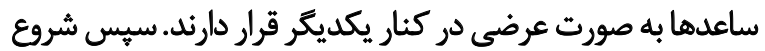

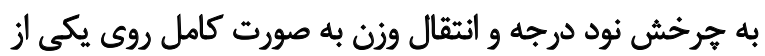

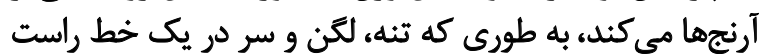

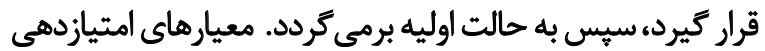

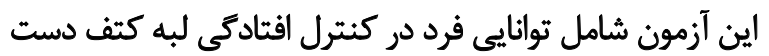

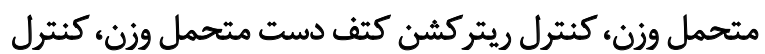

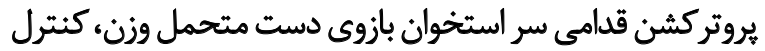

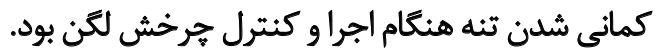

جدول r. ميائكين نمرات آزمونهاى كنترل حركت براى كروه آسيب مج يا، زائو و كروه بدون آسيب

\begin{tabular}{|c|c|c|c|}
\hline كيروه آسيب زائو & كئروه آسيب ميج يا & ئروه بلدون آسيب & متغير \\
\hline$r / 8$. & $r / M$ & $\mid / T$ & 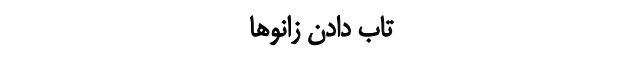 \\
\hline$r / r$ & $r / \mathcal{E}$ &.$/ 94$ & اسكات تك يا با هرخش ران \\
\hline $1 / 1+$ & V/Ar & $1 / T E$ & جرخش داخلى كنترلشده شانه \\
\hline$r / \Lambda$ & $r$ & I/RT & اسكات اسيليت و تغيير سريع يا \\
\hline$m$ & r/ge & $1 / 8 \mathrm{~V}$ & جهش روى يله از بغل و كثترل فرود روى زميين با هرخش نود درجه \\
\hline 1 & 1 &.$/ \mathrm{H}$ & يل زدن به همراه بالا و يايين آوردن يا با زانوى صاف \\
\hline r & $1 / 91$ & $\cdot / \mathrm{NA}$ & حالت جهار دست و يا وحركت دست به عقب و جلو \\
\hline$r / r$ & r/TQ & $1 / 199$ & هالكى و هرخش جائيى \\
\hline $1 / 1$ & $V / \triangle A$ & $1 / 1$ & شنا با يك بازو روى ديوار \\
\hline
\end{tabular}

مجله بيومكانيك ورنش 
جدول r. نتايج آزمون شفه بين كروه آسيب ميج يا، زانو و كروه بدون آسيب در امتياز آزمونهاى كنترل حركت

\begin{tabular}{|c|c|c|c|c|}
\hline معنادارى & خطاى استاندارد & تفاوت ميانكين & آماروهاى استنباطى & مقايسه بين كروهى \\
\hline$\%$ & $\cdot / \Delta V A$ & จ/94 & كروه آسيب معج يا & كروه بدون آسيب \\
\hline$\%$ & .19 .8 & $1 . / 9 r$ & كروه آسيب زانو & كروه بدون آسيب \\
\hline $.1 .8 \mathrm{~V}$ & .1958 & V/PT & كروه آسيب زانو & كروه آسيب ميج جا \\
\hline
\end{tabular}

مجله بيومكانيك ورنشـ

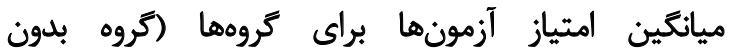
آسيب=fl/ff

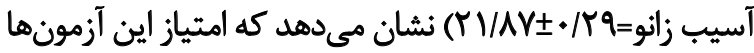

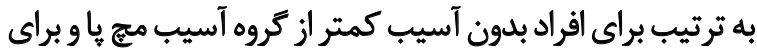

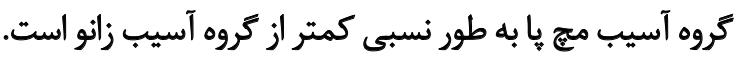

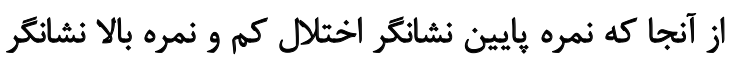

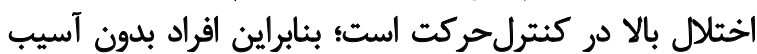

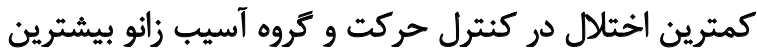

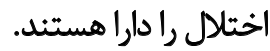
همجينين با توجه به نتايج آزمونهاي آمارى ANOVA، بين

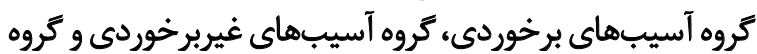

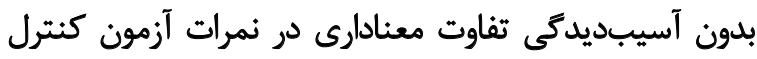

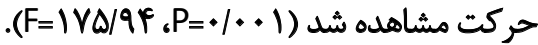

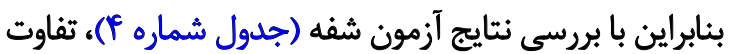

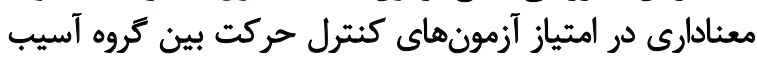

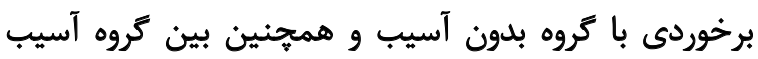

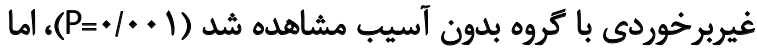

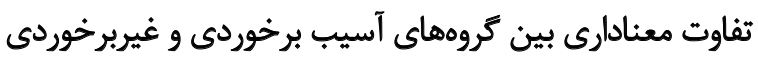

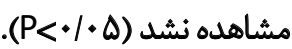

با توجه به ميانكين امتياز آزمونها براي كروهها (كروه بدون

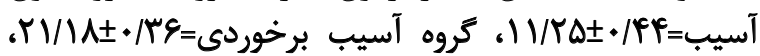

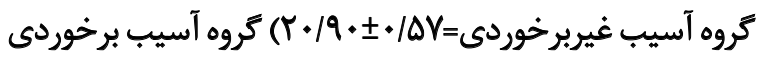
نمرات بالاترى نسبت به كروه آسيب غيربرخيت نشانكر اختلال بيشتر در كنترل حركت است. با توجه به اينكه مطالعاتى كه ثاكنون در ارتباط با آزمونهاي
حركت و سابقه آسيبديدگى از آزمون آناليز واريانس يكراهـ

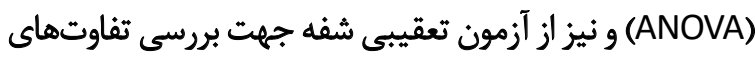

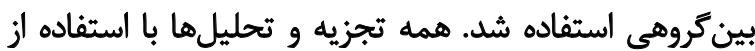

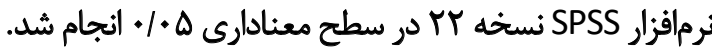

نتايج

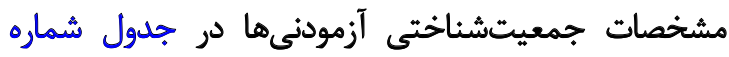

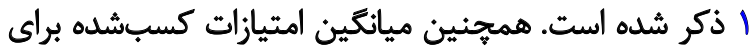

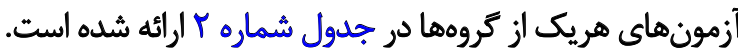

جهت اجراى آزمون آمارى تحليل واريانس يكراهه (ANOVA)

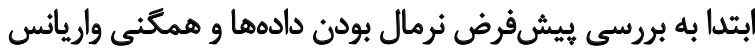

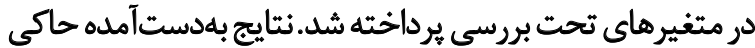

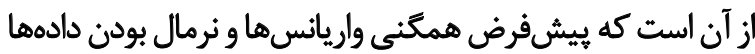
(P< در تمامى متغيرهاى ثرُوهش برقرار است

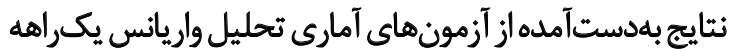

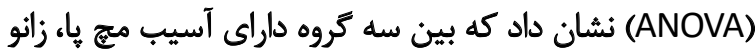

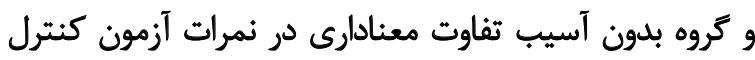

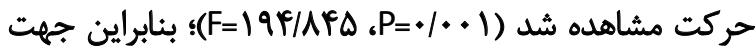

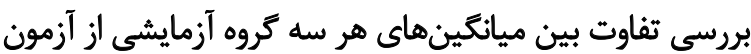

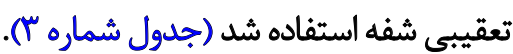

با توجه به نتايج آزمون شفه، تفاوت معنادارى در امتياز

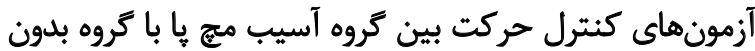

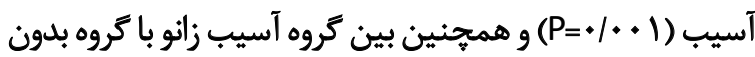

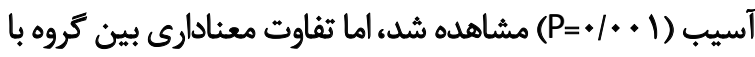

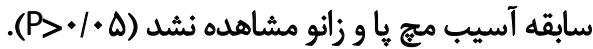

جدول F. نتايج آزمون شفه كروهماى آسيب برخوردى و غيربرخوردى و كروه بدون آسيب در امتياز آزمونهاى كنترل حركت

\begin{tabular}{|c|c|c|c|c|}
\hline معنادارى & خطاى استاندارد & تفاوت ميانكين & آمارههاى استنباطى & مقايسه بين كروهى \\
\hline$\%$ & Mre & q/90 & آسيب برخوردى & بدون آسيب \\
\hline$\%$ & .109 & var & آسيب غيريرخوردى & بدون آسيب \\
\hline ./941 & . MrY &.$/ T \Lambda$ & آسيب غيربرخوردى & آسيب برخوردى \\
\hline
\end{tabular}

مجله بيومكانيك ورنش 


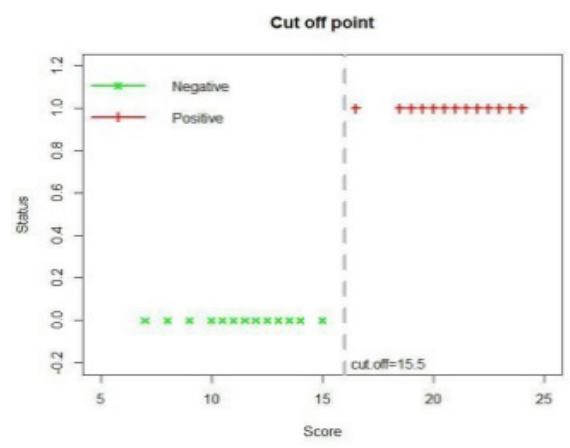

مجله بيومكانيك ورنث

تصوير Y. تعيين نقطه بيشبين ROC آزمون كنترل حركت كروه آسيبهاي غيربرخوردى و زروه

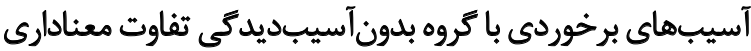

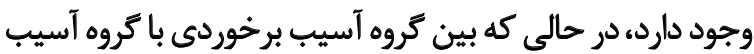

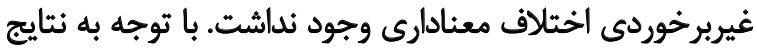

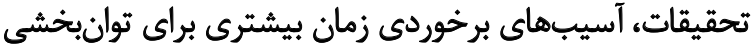

كامل و بازگشت به ورزش نياز داريب دارند [IV]

وجود درد، عاملى كنترل كننده براى فرد محسوب ميشود و

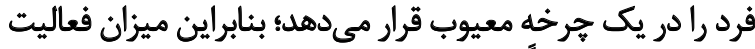

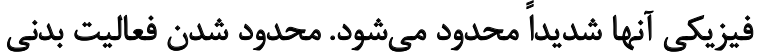

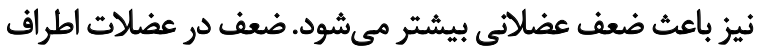

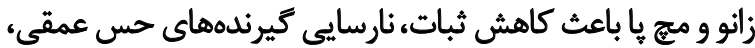

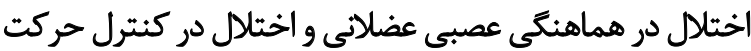

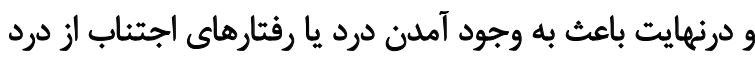
مي شود.

از طرفي با توجه به اينكه آسيب در افراد داراي آسيبهاي

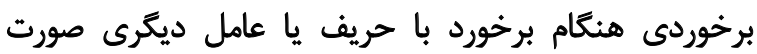

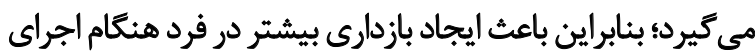

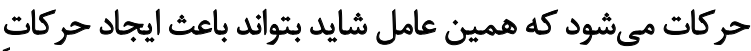

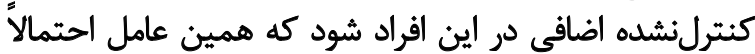

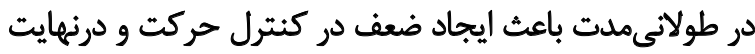
كسب نمرات ضعيفتر در آزمونهاى كنترل حركت شده است.

مطالعات بسيارى ارتباط بين آزمونهاي غربالكرى و وقوع

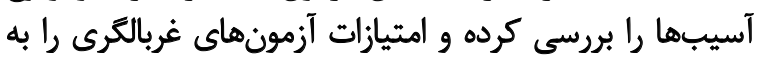

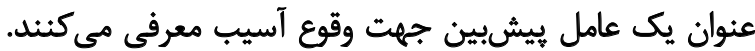
براى مثال، تحقيق روى فوتباليستهاى حرفهاي نشان نشان داد كه

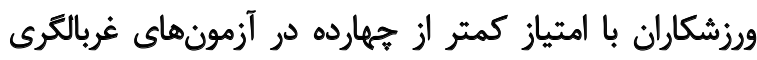

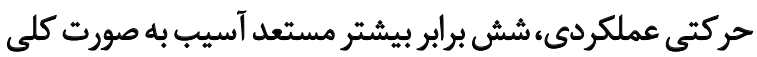

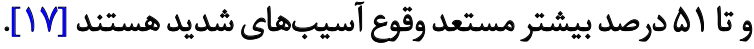

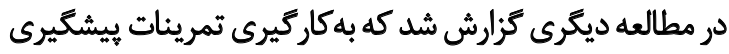

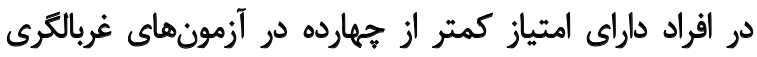

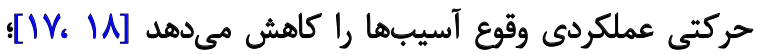

غُبالعرى كنترل حركت صورت كرفته است به به بيشبينى امتيازات كنترل حركت و وقوع آسيب اشاره نداشتهاند، مطالعه

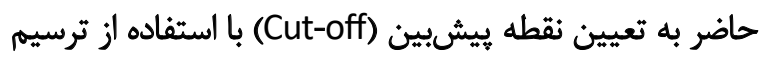

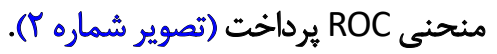
يك روش مؤثر و شناختهشده در ارزيابي يك تست آزمايشغاهي

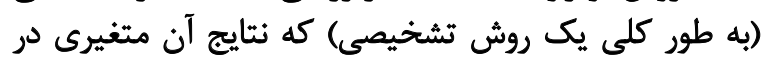

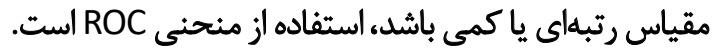

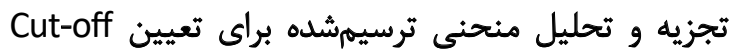

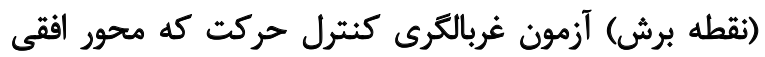

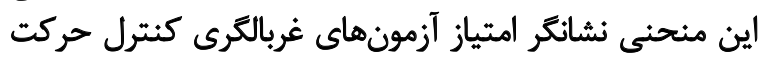

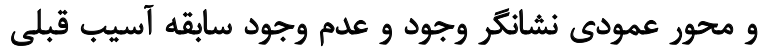

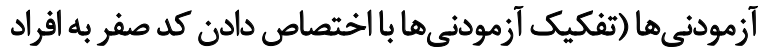

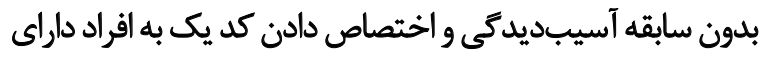

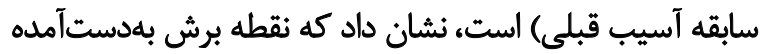

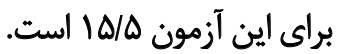

ثै

هدف از اين يُروهش، بررسى ارتباط بين امتياز آزمونهاى

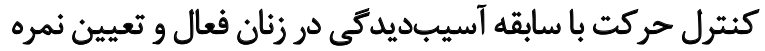

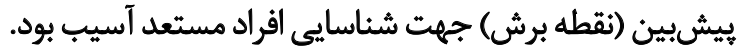

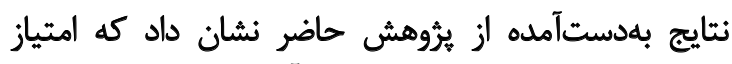

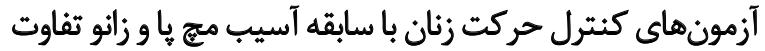

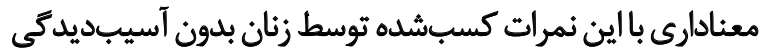

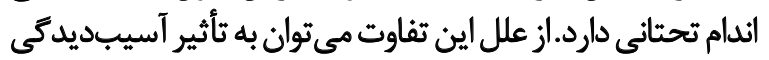

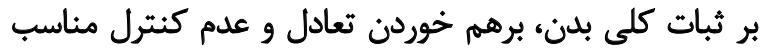

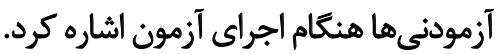

اما با وجود اينكه امتياز اين آزمونها براى كروه آسيب مج معزي

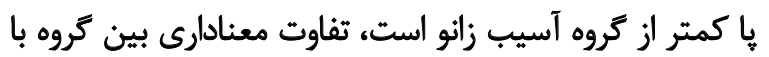

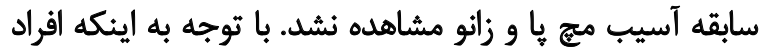

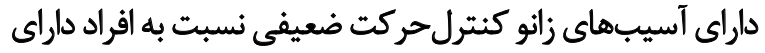

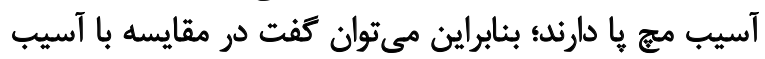

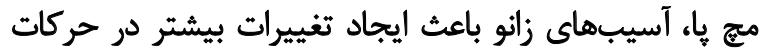

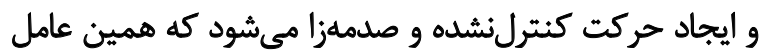

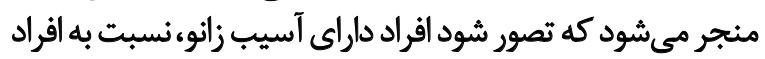

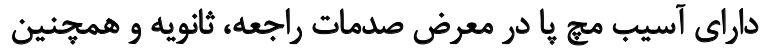
ايجاد ديكر اختلالات قرار دارند.

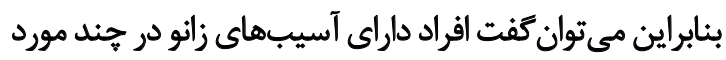

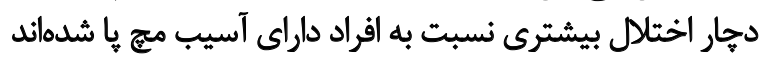

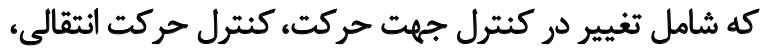
كنترل دامنه حركتى و كنترل قابليت كشسانى است همجنين نتايج بهدست آمده حاكى از آن است كه بين نمرات 


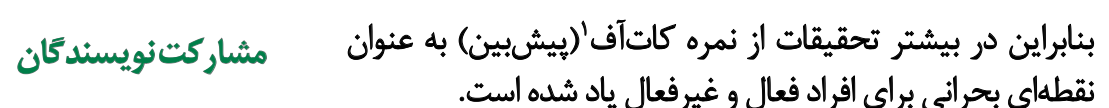
تمام نويسندكان در طراحى، اجرا و نكارش همه بخشهاى ئروهش حاضر مشاركت داشتهاند.

$$
\text { تعارض منافع }
$$

بنابر اظهار نويسندكان اين مقاله تعارض منافع ندارد.

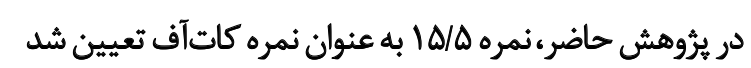

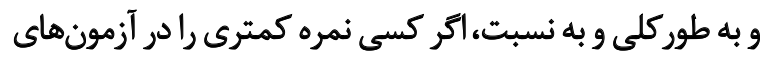

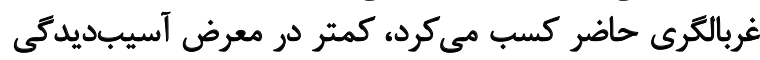

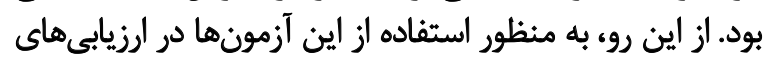

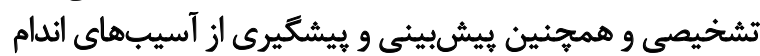

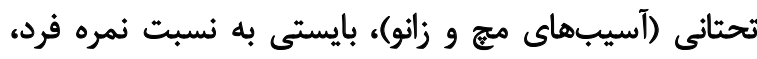
احتمال آسيبديدكى فرد را تخمين زاندان بايني

\section{نتيجه تيرى نهايي}

تحقيق حاضر يكى از اولين تحقيقات انجامشده در زميند

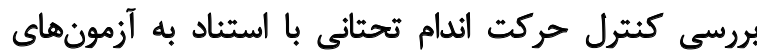

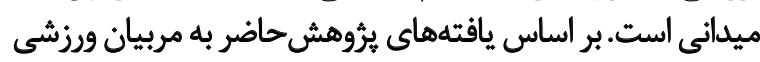

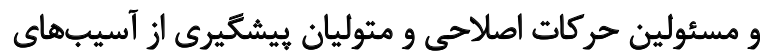

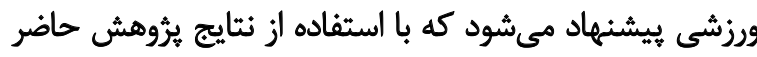

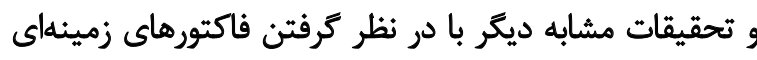

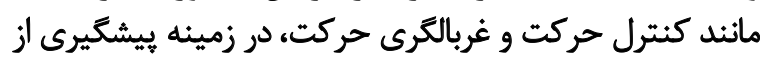

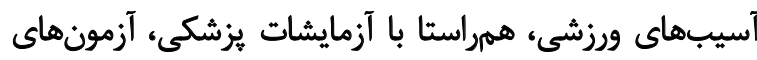

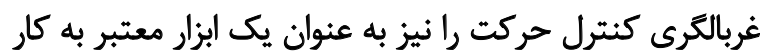

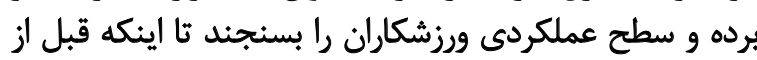

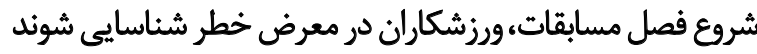

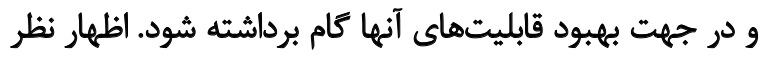

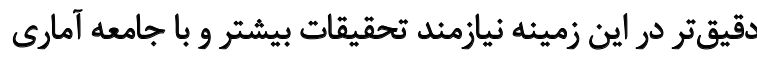

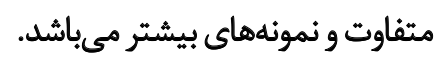
مالاحظات اخلاقي - اتي

$$
\text { يبروى از اصول اخلاق يثوهش }
$$

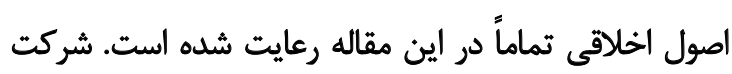

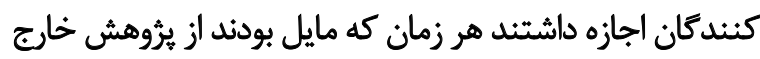

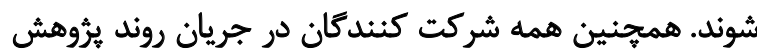
بودند. اطلاعات آن ها محرمانه نكَه داشته شد شدان

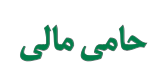

مقاله حاضر از يايان نامه كارشناسى ارشد نويسنده اول در كروه

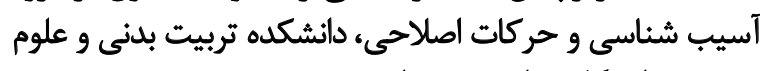
ورزشى، دانشًاه خوارزمى، تهران. 


\section{Reference}

[1] Agel J, Olson DE, Dick R, Arendt EA, Marshall SW, Sikka RS. Descriptive epidemiology of collegiate women's basketball injuries: National Collegiate Athletic Association Injury Surveillance System, 1988-1989 through 2003-2004. J Athl Train. 2007; 42(2):202-10. [PMID] [PMCID]

[2] Conn J, Annest JL, Gilchrist J. Sports and recreation related injury episodes in the US population, 1997-99. Inj Pre. 2003; 9(2):117-23. [DOI:10.1136/ip.9.2.117] [PMID] [PMCID]

[3] Hootman JM, Dick R, Agel J. Epidemiology of collegiate injuries for 15 sports: summary and recommendations for injury prevention initiatives. J Athl Train. 2007;42(2):311. [PMID] [PMCID]

[4] Leetun DT, Ireland ML, Willson JD, Ballantyne BT, Davis IM. Core stability measures as risk factors for lower extremity injury in athletes. Med Sci Sports Exerc. 2004; 36(6):926-34. [DOI:10.1249/01. MSS.0000128145.75199.C3] [PMID]

[5] Devan MR, Pescatello LS, Faghri P, Anderson J. A prospective study of overuse knee injuries among female athletes with muscle imbalances and structural abnormalities. J Athl Train. 2004; 39(3):263-7. [PMID] [PMCID]

[6] Taunton JE, Ryan MB, Clement D, McKenzie DC, Lloyd-Smith D, Zumbo B. A retrospective case-control analysis of 2002 running injuries. $\mathrm{Br}$ Sports Med. 2002; 36(2):95-101. [DOI:10.1136/bjsm.36.2.95] [PMID] [PMCID]

[7] Shojaedin SS, Letafatkar A, Hadadnezhad M, Dehkhoda MR. Relationship between Functional Movement Screen (FMS) score and the history of injury and identify predictive value of the FMS. Int J Inj Contr Saf Promot. 2014; 21(4):355-60. [DOI:10.1080/17457300.2013.833942 ] [PMID]

[8] Hergenroeder AC. Prevention of sports injuries. Pediatrics. 1998; 101(6):1057-63. tent/101/6/1057.short

[9] Mischiati CR, Comerford M, Gosford E, Swart J, Ewings S, Botha N, et al. Intra and inter-rater reliability of screening for movement impairments: Movement control tests from the foundation matrix. I Sports Sci Med. 2015; 14(2):427-40. [PMID] [PMCID]

[10] Myer GD, Ford KR, Khoury J, Succop P, Hewett TE. Biomechanics laboratory-based prediction algorithm to identify female athletes with high knee loads that increase risk of ACL injury. Br I Sports Med. 2011; 45(4):245-52. [DOI:10.1136/bjsm.2009.069351] [PMID] [PMCID]

[11] Hewett TE, Myer GD, Ford KR, Heidt RS, Colosimo AJ, McLean SG, et al. Biomechanical measures of neuromuscular control and valgus loading of the knee predict anterior cruciate ligament injury risk in female athletes: A prospective study. Am J Sports Med. 2005; 33(4):492-501. [DOI:10.1177/0363546504269591] [PMID]

[12] Hewett TE, Lindenfeld TN, Riccobene JV, Noyes FR. The effect of neuromuscular training on the incidence of knee injury in female athletes: $\mathrm{A}$ prospective study. Am J Sports Med. 1999; 27(6):699-706. [DOI:10.1177 /0363546599027006030] [PMID]

[13] McNeill W. The double knee swing test: A practical example of the Performance Matrix Movement Screen. J Bodyw Mov Ther. 2014; 18(3):477-81. [DOI:10.1016/j.jbmt.2014.05.008] [PMID]

[14] Mottram S, Comerford M. A new perspective on risk assessment. Phys Ther Sport. 2008; 9(1):40-51. [DOI:10.1016/j.ptsp.2007.11.003] [PMID]

[15] Imwalle LE, Myer GD, Ford KR, Hewett TE. Relationship between hip and knee kinematics in athletic women during cutting maneuvers: A possible link to noncontact anterior cruciate ligament injury and prevention. J Strength Cond Res. 2009; 23(8):2223-30. [DOI:10.1519/ JSC.0b013e3181bc1a02] [PMID] [PMCID]
[16] Quatman CE, Hewett TE. The anterior cruciate ligament injury controversy: Is "valgus collapse" a sex-specific mechanism? Br J Sports Med. 2009; 43(5):328-35. [DOI:10.1136/bjsm.2009.059139] [PMID] [PMCID]

[17] Kiesel K, Plisky P, Butler R. Functional movement test scores improve following a standardized off-season intervention program in professional football players. Scand J Med Sci Sports. 2011; 21(2):287-92. [DOI:10.1111/j.1600-0838.2009.01038.x] [PMID]

[18] Kiesel K, Plisky PJ, Voight ML. Can serious injury in professional football be predicted by a preseason functional movement screen? N Am J Sports Phys Ther. 2007; 2(3):147-58. [PMID] [PMCID] 